\title{
Influence of microbiota and metabolites on the quality of tobacco during fermentation
}

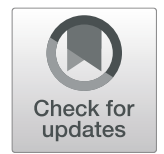

Jingjing Li ${ }^{1}$, Yuanyuan Zhao' ${ }^{1}$ Yanqing Qin ${ }^{2}$ and Hongzhi Shi ${ }^{{ }^{*}}$

\begin{abstract}
Background: To explore the optimum fermentation conditions for tobacco leaves and also screen the microbiota and metabolites that are beneficial for fermentation.

Methods: Tobacco leaves were fermented at $25^{\circ} \mathrm{C}, 35^{\circ} \mathrm{C}$, and $45^{\circ} \mathrm{C}$ for 2,4 , and 6 weeks, respectively. For identification of the best fermentation temperature, physicochemical properties and sensory quality of fermented tobacco were investigated. Subsequently, based on the appropriate temperature, $16 \mathrm{~s}$ rRNA sequencing and metabolomics analysis of tobacco were performed to monitor the change of microbes and metabolites during fermentation process (from 2 to 6 weeks).

Results: Sensory quality analysis indicated that fermentation at $45^{\circ} \mathrm{C}$ for 6 weeks represented the optimum condition. Metabolomics analysis showed that a total of 415 metabolites were annotated. The increase of fermentation period led to significant changes of metabolites. Results revealed an increase in concentration of Lphenylalanine and sphingosine as well as decreased concentration of betaine and phytosphingosine with the prolongation of fermentation period ( 2 to 6 weeks). Distinct changes in the microbiota were also observed with prolongation of the fermentation time. Results revealed that Pseudomonas, Pantoea, and Burkholderia were dominant bacteria in fermentation at $45^{\circ} \mathrm{C}$ for 6 weeks. With the extension of the fermentation time, the abundance of Pseudomonas increased, while that of Sphingomonas and Methylobacterium decreased. Furthermore, microbiota profiles were tightly relevant to the altered metabolites, especially compounds involved in the sphingolipid metabolism.
\end{abstract}

Conclusion: Suitable fermentation conditions were $45^{\circ} \mathrm{C}$ for 6 weeks; phytosphingosine and sphingosine might affect tobacco fermentation via the sphingolipid metabolism pathway. This study provides a theoretical basis for guiding tobacco fermentation and gives insights into reducing harmful substances during tobacco fermentation.

Keywords: Tobacco fermentation, Temperature, Time, Microbiota, Metabolites

\section{Background}

Tobacco (Nicotiana tabacum L.) is one of the most economically important non-food cultivated products in the world [1]. China is the largest producer and consumer of tobacco worldwide, according for approximately one-third of total global consumption each year. Statistically, 315 million smokers in China consume 44\%

\footnotetext{
* Correspondence: shihongzhi@henau.edu.cn

${ }^{1}$ College of Tobacco Science, Henan Agricultural University, No. 95 Wenhua Road, Zhengzhou 450002, Henan Province, China

Full list of author information is available at the end of the article
}

of the world's cigarettes [2]. To our knowledge, fermentation, also known as aging, is an essential process for improving the qualities of tobacco [3]. The unaged tobacco leaves cannot be directly utilized in cigarette production due to their insufficient fragrance as well as irritating smoke [4]. The fermentation process causes the tobacco to have high commercial quality and turns its color to dark yellow, eliminating harmful odors, degrading harmful substances, reducing offensive odor, and producing tobacco-specific flavors $[5,6]$.

(c) The Author(s). 2020 Open Access This article is licensed under a Creative Commons Attribution 4.0 International License, which permits use, sharing, adaptation, distribution and reproduction in any medium or format, as long as you give appropriate credit to the original author(s) and the source, provide a link to the Creative Commons licence, and indicate if changes were made. The images or other third party material in this article are included in the article's Creative Commons licence, unless indicated otherwise in a credit line to the material. If material is not included in the article's Creative Commons licence and your intended use is not permitted by statutory regulation or exceeds the permitted use, you will need to obtain permission directly from the copyright holder. To view a copy of this licence, visit http://creativecommons.org/licenses/by/4.0/ The Creative Commons Public Domain Dedication waiver (http://creativecommons.org/publicdomain/zero/1.0/) applies to the data made available in this article, unless otherwise stated in a credit line to the data. 
Stacked fermentation is a common type of fermentation [7]. Under the condition of certain moisture content, tobacco leaves are stacked into a pile. Relying on the heat generated by the self-heating action of tobacco, it promotes the biochemical changes in leaves and improves the quality and processing characteristics of tobacco. During this process, heat is not easily dissipated due to the poor thermal conductivity of the tobacco bulk itself, and the temperature in the stack can rise to 55$65^{\circ} \mathrm{C}$. After $5-7$ days of fermentation, periodic flipping of the tobacco bulk is conducted to improve fermented tobacco homogeneity and avoid overheating. This process is repeated $2-5$ times and the fermentation is basically over [8]. Generally, the common artificial fermentation temperatures range from 35 to $50{ }^{\circ} \mathrm{C}$ with a fermentation cycle of 4-7 weeks [9]. However, due to the different producing area, year, variety, grade, and maturity of tobacco leaves, the optimum fermentation conditions of tobacco are various [10]. For instance, Yang et al. [11] found that Leshan Jiajiang tobacco (a type of cigar, GQH-J1) was suitable for fermentation at a temperature of $45^{\circ} \mathrm{C}$ and a relative humidity (RH) of $85 \%$ for 40 days. Our previous study suggested that the optimum conditions for cigar filler tobacco fermentation were $45^{\circ} \mathrm{C}$ and $\mathrm{RH} 80 \%$ [12]. Furthermore, undesirable fermentation by-products are produced during the fermentation process, such as tobacco-specific nitrosamines (TSNAs), whose increase in concentration parallels that of nitrite [13]. Another unpleasant by-product of organic acid metabolism is oxalic acid, which can negatively affect the taste of tobacco [14]. Notably, TSNAs play a central role in tobacco-smoke mediated cancer initiation [15]. Taken together, minimizing the production of TSNAs and nitrite is a major goal of tobacco fermentation technology [16].

Reportedly, fermentation not only is a chemical reaction process, but also is linked to the enzymatic action of microbes, which play extremely vital roles in this process [17]. Di Giacomo et al. [18] revealed that Staphylococcaceae and Lactobacillales were dominant detected bacteria in the early fermentation, whereas Actinomycetales rapidly expanded during the late phase. Meanwhile, several microorganism strains, such as AS97 (a kind of Pseudomonas fluorescens, Genbank accession number: JF449445) [19] and cellulose degradation bacteria [20], have the ability to reduce TSNAs in cigarettes, which can potentially be applied for industrial tobacco fermentation. Besides, changes in chemical compositions and metabolites in the tobacco fermentation process have been found [21, 22]. Previous study indicated that the organic acid content, volatile acid, and volatile carbonyl compounds were increased, while total nitrogen, nicotine, protein, and amino acids were decreased during the fermentation process [5]. Besides, polyphenols are converted into aroma substances via oxidative degradation, which improves the aroma of cigarette [23]. Despite the studies mentioned above, few studies have systematically investigated the changes of microbiota composition and metabolites during the tobacco fermentation. Thus, in order to improve the quality of the end product and possibly improve its safety, it is necessary to determine the type of microorganisms and metabolites that play roles in this process and to identify the optimal fermentation conditions.

In the present study, we selected Shiyan No.1 as the research material to investigate its optimal fermentation condition and explore changes in microbiota and metabolites during fermentation. Concretely, the tobacco leaves were fermented at $25^{\circ} \mathrm{C}, 35^{\circ} \mathrm{C}$, and $45^{\circ} \mathrm{C}$ for 2,4 , and 6 weeks, respectively. According to the physiological indicators and sensory evaluation of fermented tobacco leaves, the optimal conditions of tobacco fermentation were obtained. Then, based on optimal temperature, we identified the altered microorganisms and metabolites during the fermentation process (2, 4 and 6 weeks) by using $16 \mathrm{~s}$ rRNA gene sequencing and liquid chromatography-mass spectrometry (LC-MS) analysis.

\section{Results}

\section{Sensory quality assessment}

The content of the aroma components is listed in Table 1. The results showed that the levels of major neutral aroma components, such as solanone, geranylacetone, dihydroactinidiolide, and megastigmatrienone, were elevated with the increase in fermenting temperature. These components played vital roles in producing fragrances and increasing the concentration of tobacco smoke. In addition, the neophytadiene content was the highest at $45^{\circ} \mathrm{C} \mathrm{com}$ pared with the others. The neophytadiene could enhance aroma, reduce irritants and alcohol, and was considered as one of the key ingredients that contributed the most to the aroma of tobacco. Thus, $45^{\circ} \mathrm{C}$ fermentation was the most conducive to the accumulation of aroma components in tobacco leaves.

Meanwhile, with the increase of fermentation temperature and time, the content of TSNAs raised significantly (Table 2, Supplementary Figure 1A and 1B), while the level of alkaloids and nitrates decreased evidently (Table 3, Supplementary Figure $1 \mathrm{C}$ and 1D), suggesting that the accumulation of harmful substances in smoke declined to some extent at $45^{\circ} \mathrm{C}$ fermenting. Furthermore, with the increase of temperature, the aroma quality and quantity of tobacco gradually increased, the irritation was eliminated, and the aftertaste was comfortable (Table 4). Taken together, the quality detection and sensory analysis showed that $45^{\circ} \mathrm{C}$ fermenting for 6 weeks was the optimal fermentation condition. 
Table 1 The content of aroma components of tobacco leaves in different groups

\begin{tabular}{|c|c|c|c|c|c|c|c|c|c|c|}
\hline \multirow[t]{2}{*}{ Components $(\mu \mathrm{g} / \mathrm{g})$} & \multicolumn{10}{|l|}{ Groups } \\
\hline & control & $\begin{array}{l}25^{\circ} \mathrm{C} / 2 \\
\text { weeks }\end{array}$ & $\begin{array}{l}25^{\circ} \mathrm{C} / 4 \\
\text { weeks }\end{array}$ & $\begin{array}{l}25^{\circ} \mathrm{C} / 6 \\
\text { weeks }\end{array}$ & $\begin{array}{l}35^{\circ} \mathrm{C} / 2 \\
\text { weeks }\end{array}$ & $\begin{array}{l}35^{\circ} \mathrm{C} / 4 \\
\text { weeks }\end{array}$ & $\begin{array}{l}35^{\circ} \mathrm{C} / 6 \\
\text { weeks }\end{array}$ & $\begin{array}{l}45^{\circ} \mathrm{C} / 2 \\
\text { weeks }\end{array}$ & $\begin{array}{l}45^{\circ} \mathrm{C} / 4 \\
\text { weeks }\end{array}$ & $\begin{array}{l}45^{\circ} \mathrm{C} / 6 \\
\text { weeks }\end{array}$ \\
\hline Solanone & 4.758 & 4.938 & 5.208 & 6.655 & 7.194 & 7.447 & 7.476 & 8.439 & 12.002 & 12.008 \\
\hline Geranylacetone & 0.500 & 0.530 & 0.593 & 1.171 & 0.946 & 1.209 & 1.344 & 1.373 & 1.753 & 1.908 \\
\hline$\beta$-ionone & 0.902 & 0.877 & 0.840 & 0.752 & 0.808 & 0.782 & 0.685 & 0.801 & 0.761 & 0.603 \\
\hline Ionone oxide & 2.789 & 2.500 & 2.190 & 2.071 & 2.299 & 2.102 & 1.755 & 2.188 & 1.953 & 1.422 \\
\hline Dihydroactinidiolide & 4.224 & 4.699 & 5.247 & 6.565 & 5.868 & 7.340 & 8.350 & 7.008 & 7.608 & 8.215 \\
\hline Megastigmatrienone 1 & 0.465 & 0.503 & 0.538 & 0.555 & 0.617 & 0.709 & 0.818 & 0.829 & 0.984 & 1.024 \\
\hline Megastigmatrienone 2 & 3.154 & 3.170 & 3.355 & 3.434 & 3.732 & 4.348 & 4.695 & 4.929 & 5.811 & 6.238 \\
\hline Megastigmatrienone 3 & 0.423 & 0.489 & 0.563 & 0.572 & 0.711 & 0.818 & 0.811 & 0.931 & 1.089 & 1.082 \\
\hline $\begin{array}{l}\text { 3-hydroxy- } \beta \text { - dihydro } \\
\text { damadone }\end{array}$ & 0.236 & 0.256 & 0.305 & 0.487 & 0.750 & 0.890 & 1.067 & 1.178 & 1.644 & 1.700 \\
\hline Megastigmatrienone 4 & 2.068 & 2.104 & 2.111 & 3.963 & 4.471 & 4.911 & 5.037 & 5.434 & 6.076 & 5.689 \\
\hline 3-Oxo-a-ionol & 58.326 & 62.240 & 63.806 & 67.865 & 65.329 & 79.524 & 60.731 & 55.774 & 65.583 & 46.688 \\
\hline Neophytadiene & 338.195 & 349.413 & 362.707 & 375.111 & 351.408 & 410.975 & 422.262 & 428.902 & 492.098 & 455.894 \\
\hline 3-Hydroxysolavetivone & 3.372 & 3.697 & 4.171 & 4.295 & 3.922 & 4.200 & 5.831 & 6.092 & 6.522 & 6.558 \\
\hline$\beta$-farnesene & 7.390 & 8.511 & 11.016 & 12.015 & 9.232 & 13.111 & 12.356 & 11.184 & 14.340 & 12.271 \\
\hline $\begin{array}{l}\text { Total aroma (except } \\
\text { neophytediene) }\end{array}$ & 88.607 & 94.511 & 99.945 & 110.400 & 105.879 & 127.391 & 110.956 & 106.159 & 126.128 & 105.408 \\
\hline Total aroma & 426.802 & 443.925 & 462.651 & 485.511 & 457.287 & 538.366 & 533.218 & 535.061 & 618.226 & 561.301 \\
\hline
\end{tabular}

The tobacco leaves were fermented at $25^{\circ} \mathrm{C}, 35^{\circ} \mathrm{C}$, and $45^{\circ} \mathrm{C}(90 \%$ relative humidity), and samples were collected after 2,4 , and 6 weeks

\section{Metabolomics analysis}

\section{The principal component analysis (PCA) result}

The tobacco leaves fermented at $45^{\circ} \mathrm{C}$ for 2 weeks (group 2), 4 weeks (group 3), and 6 weeks (group 4) as well as unfermented leaves (group 1) was selected for metabolomics analysis. The metabolites of tobacco were obtained using LC-MS analysis, and the electrospray ionization of LC-MS contained positive (POS) and negative (NEG) ion modes. Generally, PCA plot could show the trend of separation between groups in the experiment. In the present study, the PCA plots of POS and
NEG revealed that samples from each group overlapped well, and there was a significant separation between group 1 and group 4 (Supplementary Figure 2). A total of 1403 and 4751 valid peaks were identified in POS and NEG modes, respectively.

\section{Metabolites annotations results}

A total of 415 metabolites identified as mentioned above were assigned to the Kyoto Encyclopedia of Genes and Genomes (KEGG) and the Human Metabolome Database (HMDB). The detail information of metabolites is

Table 2 The level of NNN, NAT, NAB, NNK, and TSNAs in tobacco leaves during fermentation process

\begin{tabular}{|c|c|c|c|c|c|}
\hline Groups & NNN (ng/g) & NAT (ng/g) & NAB (ng/g) & NNK (ng/g) & TSNAs (ng/g) \\
\hline Control & $812.73 \pm 33.2 \mathrm{Gg}$ & $1459.82 \pm 84.60 \mathrm{Ee}$ & $40.30 \pm 0.37 \mathrm{Hh}$ & $145.34 \pm 8.07 E f$ & $2458.19 \pm 126.36 \mathrm{Gf}$ \\
\hline $25^{\circ} \mathrm{C} / 2$ weeks & $934.19 \pm 31.32 \mathrm{Ff}$ & $2060.91 \pm 85.57 \mathrm{Dd}$ & $63.81 \pm 0.39 \mathrm{Gg}$ & $242.30 \pm 8.13 \mathrm{De}$ & $3301.21 \pm 125.41 \mathrm{Fe}$ \\
\hline $25^{\circ} \mathrm{C} / 4$ weeks & $1159.46 \pm 33.55 \mathrm{Ee}$ & $2274.54 \pm 83.56 C c$ & $72.49 \pm 0.36 \mathrm{Ff}$ & $293.61 \pm 8.41 \mathrm{Cd}$ & $3800.10 \pm 125.88 \mathrm{Ed}$ \\
\hline $25^{\circ} \mathrm{C} / 6$ weeks & $1546.99 \pm 36.10 \mathrm{Bb}$ & $2536.65 \pm 88.18 \mathrm{ABb}$ & $84.10 \pm 0.32 \mathrm{Dd}$ & $349.86 \pm 8.47 \mathrm{ABb}$ & $4517.60 \pm 133.06 \mathrm{BCb}$ \\
\hline $35^{\circ} \mathrm{C} / 2$ weeks & $976.51 \pm 36.06 \mathrm{Ff}$ & $2069.04 \pm 88.04 \mathrm{Dd}$ & $72.81 \pm 0.35 \mathrm{Ff}$ & $246.66 \pm 8.22 \mathrm{De}$ & $3365.03 \pm 132.67 \mathrm{Fe}$ \\
\hline $35^{\circ} \mathrm{C} / 4$ weeks & $1251.87 \pm 35.24 \mathrm{Dd}$ & $2394.27 \pm 84.81 \mathrm{BCbc}$ & $84.34 \pm 0.30 \mathrm{Dd}$ & $300.26 \pm 8.37 C d$ & $4030.73 \pm 128.72 \mathrm{DEd}$ \\
\hline $35^{\circ} \mathrm{C} / 6$ weeks & $1602.03 \pm 39.96 \mathrm{Bb}$ & $2694.59 \pm 80.05 \mathrm{Aa}$ & $90.19 \pm 0.35 \mathrm{Bb}$ & $354.84 \pm 8.07 \mathrm{ABab}$ & $4741.66 \pm 128.43 \mathrm{ABa}$ \\
\hline $45^{\circ} \mathrm{C} / 2$ weeks & $1192.84 \pm 33.58 \mathrm{DEde}$ & $2294.08 \pm 89.99 C c$ & $73.86 \pm 0.34 \mathrm{Ee}$ & $287.15 \pm 8.22 \mathrm{Cd}$ & $3847.94 \pm 132.12 \mathrm{Ed}$ \\
\hline $45^{\circ} \mathrm{C} / 4$ weeks & $1439.20 \pm 31.50 C c$ & $2407.34 \pm 89.62 \mathrm{BCbc}$ & $86.59 \pm 0.36 C c$ & $335.67 \pm 8.30 \mathrm{BC}$ & $4268.80 \pm 129.78 C D C$ \\
\hline $45^{\circ} \mathrm{C} / 6$ weeks & $1685.79 \pm 38.24 \mathrm{Aa}$ & $2720.40 \pm 84.92 \mathrm{Aa}$ & $95.80 \pm 0.34 \mathrm{Aa}$ & $367.12 \pm 8.14 \mathrm{Aa}$ & $4869.12 \pm 131.63 \mathrm{Aa}$ \\
\hline
\end{tabular}


Table 3 The level of alkaloids and nitrate of tobacco leaves in different groups

\begin{tabular}{lllllll}
\hline Groups & Nicotine $(\boldsymbol{\mu g} / \mathbf{g})$ & Nornicotine $(\boldsymbol{\mu g} / \mathbf{g})$ & Neonicotine $(\boldsymbol{\mu g} / \mathbf{g})$ & Anatabine $(\boldsymbol{\mu g} / \mathbf{g})$ & Total alkaloids $(\%)$ & Nitrate $(\boldsymbol{\mu g} / \mathbf{g})$ \\
\hline Control & $5.16 \pm 0.07$ & $0.24 \pm 0.01$ & $0.05 \pm 0.00$ & $0.48 \pm 0.02$ & $5.92 \pm 0.10 \mathrm{Aa}$ & $3589.33 \pm 52.78 \mathrm{Aa}$ \\
$25^{\circ} \mathrm{C} / 2$ weeks & $4.90 \pm 0.07$ & $0.21 \pm 0.01$ & $0.04 \pm 0.00$ & $0.41 \pm 0.02$ & $5.56 \pm 0.10 \mathrm{Bb}$ & $3354.15 \pm 52.20 \mathrm{Bb}$ \\
$25^{\circ} \mathrm{C} / 4$ weeks & $4.69 \pm 0.08$ & $0.19 \pm 0.01$ & $0.04 \pm 0.00$ & $0.41 \pm 0.02$ & $5.33 \pm 0.10 \mathrm{BC}$ & $3160.14 \pm 52.29 \mathrm{Ccd}$ \\
$25^{\circ} \mathrm{C} / 6$ weeks & $4.24 \pm 0.08$ & $0.18 \pm 0.01$ & $0.03 \pm 0.00$ & $0.36 \pm 0.02$ & $4.82 \pm 0.12 \mathrm{CDde}$ & $2991.19 \pm 54.31 \mathrm{DEe}$ \\
$35^{\circ} \mathrm{C} / 2$ weeks & $4.35 \pm 0.08$ & $0.20 \pm 0.01$ & $0.03 \pm 0.00$ & $0.40 \pm 0.02$ & $4.98 \pm 0.11 \mathrm{Cd}$ & $3210.28 \pm 56.96 \mathrm{CC}$ \\
$35^{\circ} \mathrm{C} / 4$ weeks & $4.25 \pm 0.08$ & $0.18 \pm 0.01$ & $0.03 \pm 0.00$ & $0.38 \pm 0.02$ & $4.85 \pm 0.12 \mathrm{CDde}$ & $2938.96 \pm 55.11 \mathrm{Ee}$ \\
$35^{\circ} \mathrm{C} / 6$ weeks & $4.11 \pm 0.06$ & $0.16 \pm 0.01$ & $0.03 \pm 0.00$ & $0.35 \pm 0.02$ & $4.65 \pm 0.12 \mathrm{DEef}$ & $2674.46 \pm 58.02 \mathrm{FGg}$ \\
$45^{\circ} \mathrm{C} / 2$ weeks & $4.31 \pm 0.09$ & $0.19 \pm 0.01$ & $0.03 \pm 0.00$ & $0.38 \pm 0.02$ & $4.91 \pm 0.10 \mathrm{CDd}$ & $3094.13 \pm 51.96 \mathrm{CDd}$ \\
$45^{\circ} \mathrm{C} / 4$ weeks & $4.20 \pm 0.08$ & $0.18 \pm 0.01$ & $0.03 \pm 0.00$ & $0.37 \pm 0.02$ & $4.78 \pm 0.13 \mathrm{CDde}$ & $2785.81 \pm 57.53 \mathrm{Ff}$ \\
$45^{\circ} \mathrm{C} / 6$ weeks & $3.96 \pm 0.06$ & $0.16 \pm 0.01$ & $0.03 \pm 0.00$ & $0.35 \pm 0.02$ & $4.50 \pm 0.12 \mathrm{Ef}$ & $2569.76 \pm 53.03 \mathrm{Gh}$ \\
\hline
\end{tabular}

Control group represents the sun-dried unfermented tobacco leaves. All data are represented by mean \pm SD $(n=3)$. Uppercase letters indicate $p$-value $<0.05$ and lowercase letters indicate $p$-value $<0.01$

shown in Supplementary Table 1. These metabolites were classified into $93 \mathrm{HMDB}$ subclasses and 11 HMDB superclasses (Fig. 1a and b). Among these, 192 metabolites were included in the "lipids and lipid-like molecules" term, which accounted for the majority of all classes (53.19\%). "Organic acids and derivatives" (14.4\%) and "organo-heterocyclic compounds" (10.53\%) were also enriched by identified metabolites.
KEGG pathways analysis showed that 415 metabolites were divided into seven categories, including metabolism, genetic information processing, environmental information processing, cellular processes, organismal systems, human diseases, and drug development (Fig. 1c). For the "metabolism" term, the major pathways were "amino acid metabolism", followed by "lipid metabolism", "biosynthesis of other secondary metabolites",

Table 4 The sensory evaluation of fermented tobacco

\begin{tabular}{|c|c|c|c|c|c|c|c|c|c|}
\hline Groups & $\begin{array}{l}\text { Aroma } \\
\text { quality } \\
9-0\end{array}$ & $\begin{array}{l}\text { Aroma } \\
\text { quantity } \\
9-0\end{array}$ & $\begin{array}{l}\text { Smoke } \\
\text { density } \\
9-0\end{array}$ & $\begin{array}{l}\text { Offensive } \\
\text { odor } \\
9-0\end{array}$ & $\begin{array}{l}\text { Physiological } \\
\text { strength } \\
9-0\end{array}$ & $\begin{array}{l}\text { Irritation } \\
9-0\end{array}$ & $\begin{array}{l}\text { Aftertaste } \\
9-0\end{array}$ & $\begin{array}{l}\text { Combustibility } \\
9-0\end{array}$ & $\begin{array}{l}\text { Cigarette } \\
\text { ash } \\
9-0\end{array}$ \\
\hline Control & 3.5 & 6.0 & 6.0 & 5.0 & 8.2 & 3.0 & 3.5 & 8.0 & 8.0 \\
\hline $\begin{array}{l}25^{\circ} \mathrm{C} / 2 \\
\text { weeks }\end{array}$ & 4.5 & 6.2 & 6.0 & 5.3 & 8.0 & 3.8 & 4.0 & 8.0 & 8.0 \\
\hline $\begin{array}{l}25^{\circ} \mathrm{C} / 4 \\
\text { weeks }\end{array}$ & 5.0 & 6.5 & 6.3 & 5.5 & 7.5 & 4.5 & 5.0 & 8.0 & 8.0 \\
\hline $\begin{array}{l}25^{\circ} \mathrm{C} / 6 \\
\text { weeks }\end{array}$ & 5.7 & 6.8 & 6.5 & 5.7 & 7.3 & 5.3 & 5.3 & 8.0 & 8.0 \\
\hline $\begin{array}{l}35^{\circ} \mathrm{C} / 2 \\
\text { weeks }\end{array}$ & 5.0 & 6.3 & 6.2 & 5.5 & 7.5 & 4.5 & 5.0 & 8.0 & 8.0 \\
\hline $\begin{array}{l}35^{\circ} \mathrm{C} / 4 \\
\text { weeks }\end{array}$ & 5.5 & 6.6 & 6.3 & 5.7 & 7.3 & 5.0 & 5.3 & 8.0 & 8.0 \\
\hline $\begin{array}{l}35^{\circ} \mathrm{C} / 6 \\
\text { weeks }\end{array}$ & 5.8 & 7.0 & 6.5 & 5.8 & 7.2 & 5.5 & 5.5 & 8.0 & 8.0 \\
\hline $\begin{array}{l}45^{\circ} \mathrm{C} / 2 \\
\text { weeks }\end{array}$ & 4.7 & 6.5 & 6.3 & 5.5 & 8.0 & 4.0 & 5.0 & 8.0 & 8.0 \\
\hline $\begin{array}{l}45^{\circ} \mathrm{C} / 4 \\
\text { weeks }\end{array}$ & 5.5 & 6.8 & 6.5 & 5.8 & 7.5 & 5.2 & 5.3 & 8.0 & 8.0 \\
\hline $\begin{array}{l}45^{\circ} \mathrm{C} / 6 \\
\text { weeks }\end{array}$ & 6.0 & 7.2 & 6.8 & 6.0 & 7.3 & 5.8 & 5.8 & 8.0 & 8.0 \\
\hline
\end{tabular}

Aroma quality indicates the quality of aroma and higher scores represent better quality of aroma. Aroma quantity indicates the content of aroma and higher scores represent greater quantity of aroma. Smoke density indicates the concentration of aroma with higher scores representing higher concentration. Offensive odor indicates undesirable aromas produced by burning cigarettes, and higher scores represent less offensive odor. Physiological strength indicates the physical impact of smoke felt by smokers. The higher strength score means greater impact and stronger satisfaction. Irritation indicates slight and obvious sensory discomfort caused by smoke and higher scores represent less irritant gas. Aftertaste indicates the taste sensation after the smoke leaves the mouth and nasal cavity and higher scores mean greater aftertaste. Cigarette's Combustibility refers to the combustion characteristics of tobacco products, which is an important physical characteristic of tobacco leaves, including smoldering, burning speed, burning uniformity, burning completeness, soot color as well as cohesion. Cigarette ash indicates the color of the remaining soot after burning tobacco leaves, white is the best, followed by gray 


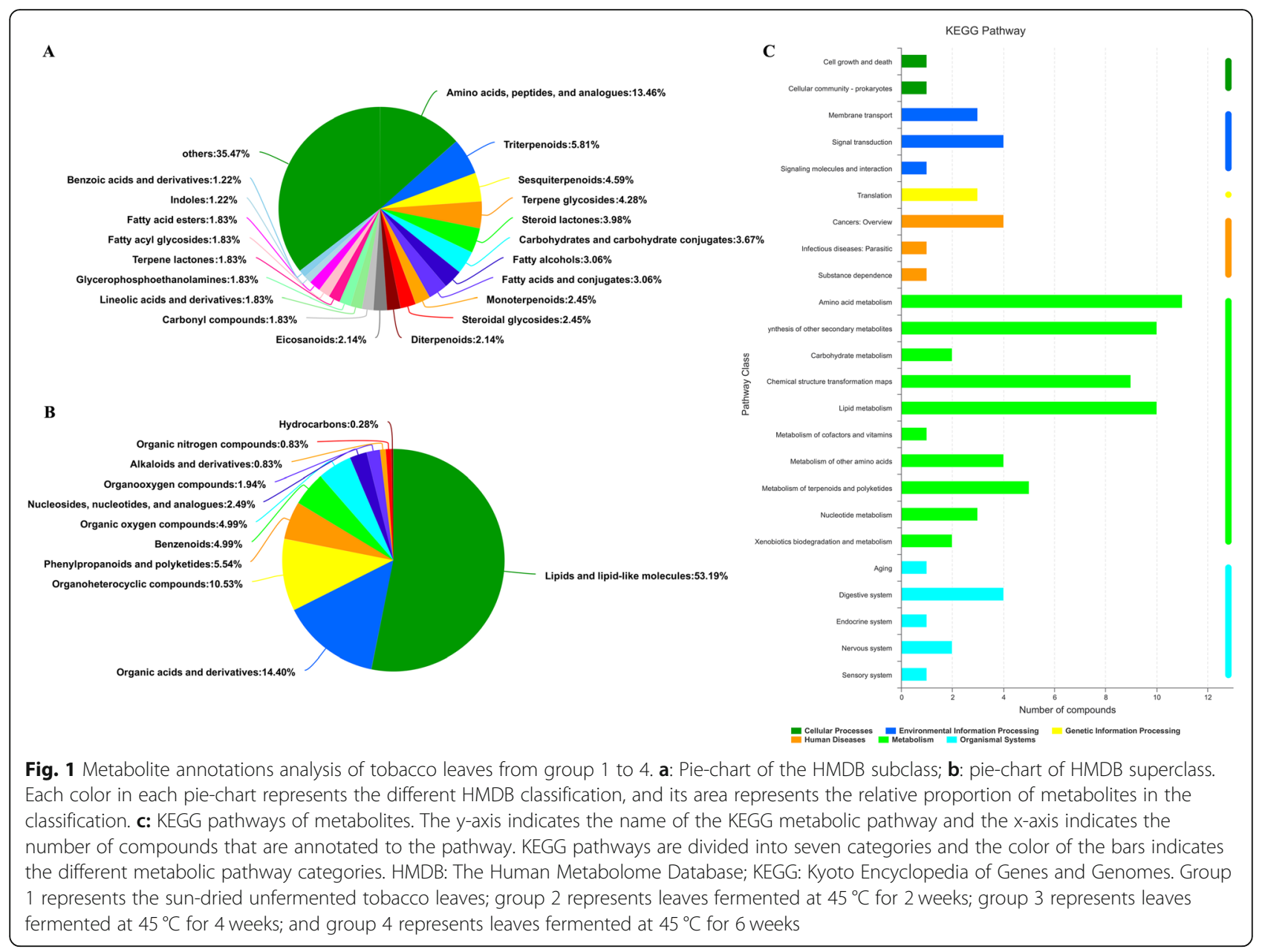

and "chemical structure transformation maps". Details of the top 20 pathways are listed in Supplementary Table 2. Notably, we found that L-phenylalanine was involved in the phenylalanine metabolism pathway (belong to amino acid metabolism); in addition, phytosphingosine and sphingosine participated in the sphingolipid metabolism pathway (belong to lipid metabolism).

\section{Multivariate analysis of differential metabolites among groups}

To screen the differential metabolites among these groups, we integrated the results of the multivariate analysis to identify the differential metabolites between any two groups. As shown in Supplementary Figure 3, the differential metabolites between control and fermentation groups were significantly separated based on the threshold variable importance in the projection (VIP) $>1$ and $p$-value $<0.05$. A total of 34 (POS) and 52 (NEG) differential metabolites were obtained between group 2 and group 1; 43 (POS) and 44 (NEG) differential metabolites were screened between group 3 and group 1; total 60 (POS) and 58 (NEG) differential metabolites were identified between group 4 and group 1 . Among these, compared with the group 1, the concentrations of Lphenylalanine and sphingosine in group 4 were increased, while the concentrations of betaine and phytosphingosine were decreased.

\section{Analysis of KEGG pathways}

Venn analysis was performed to identify the common and specific metabolites between any two groups, and 41 metabolites were shared between these four groups. In total, 15 pathways were enriched by group 2 vs. group 1, of which eight pathways were considered significant (Fig. 2a), such as sphingolipid metabolism, apoptosis, longevity regulating pathway, and biosynthesis of siderophore group nonribosomal peptides. Additionally, 18 pathways were obtained in group 3 vs. group 1 , and eight pathways were significantly enriched (Fig. 2b), which mainly included apoptosis, longevity regulating pathway, and biosynthesis of the siderophore group nonribosomal peptides. For group 4 vs. group 1, a total of 38 pathways were screened, among those, 20 pathways were found to be statistically significant (Fig. 2c). 


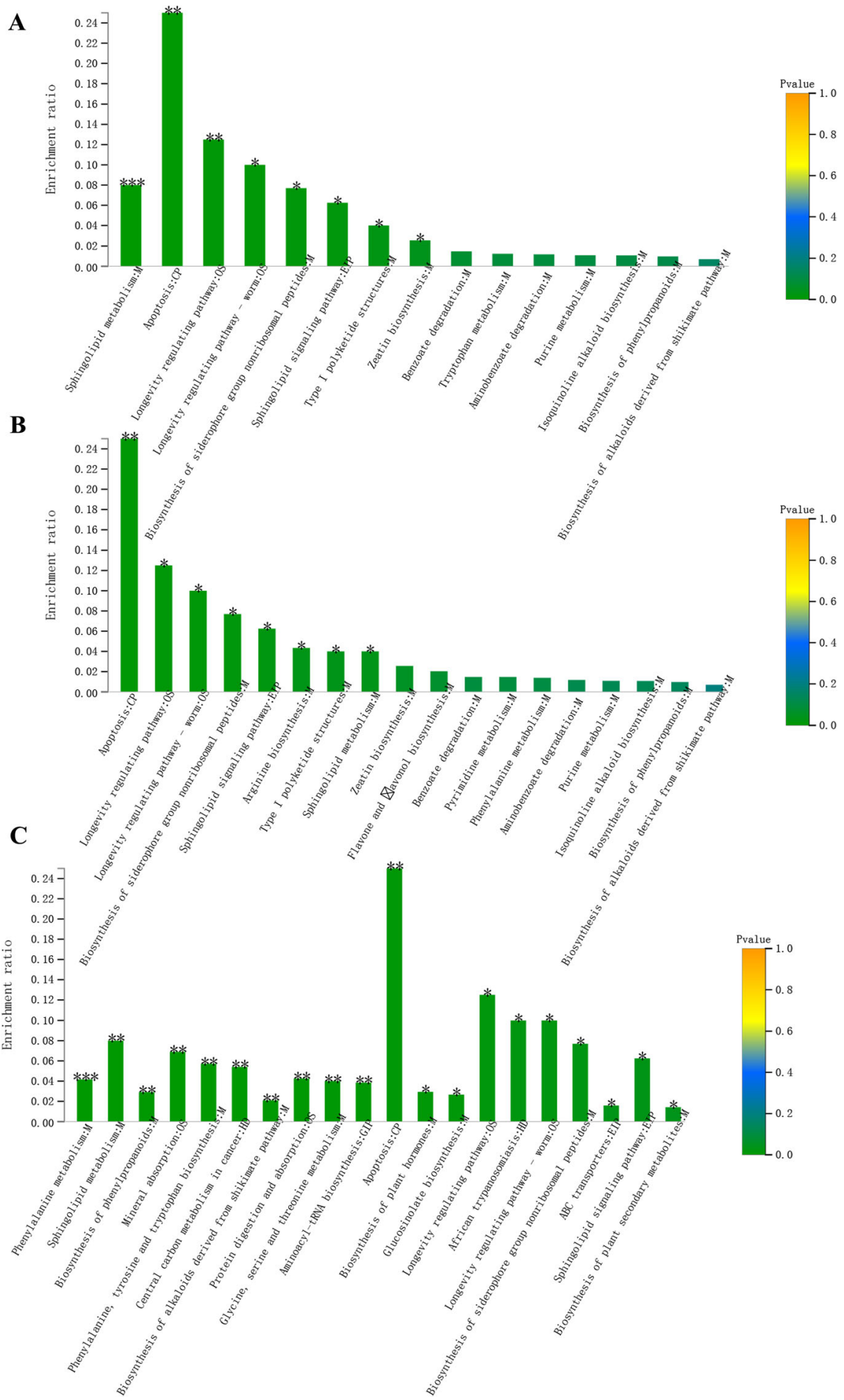

Fig. 2 KEGG analysis of differential metabolites in comparison between the two groups. a: Group 2 vs. group 1; b: group 3 vs. group 1; c: group 4 vs. group 1. The $x$-axis represents the pathway name, and the $y$-axis represents the enrichment rate. $p$-value or FDR $<0.001$ is marked as***, $p$ value or FDR $<0.01$ is marked as **, and $p$-value or FDR $<0.05$ is marked as *. Group 1 represents the sun-dried unfermented tobacco leaves; group 2 represents leaves fermented at $45^{\circ} \mathrm{C}$ for 2 weeks; group 3 represents leaves fermented at $45^{\circ} \mathrm{C}$ for 4 weeks; and group 4 represents leaves fermented at $45^{\circ} \mathrm{C}$ for 6 weeks 
These were, for example, phenylalanine metabolism, sphingolipid metabolism, and biosynthesis of phenylpropanoids. Besides, we also observed six common pathways that were involved in these groups, including sphingolipid metabolism, apoptosis, longevity regulating pathway, longevity regulating pathway worm, biosynthesis of siderophore group nonribosomal peptides, and sphingolipid signaling pathway.

\section{$16 \mathrm{~s}$ rDNA/rRNA amplicon sequencing analysis Sequences analysis}

In order to investigate the effect of microflora on tobacco fermentation, the $16 \mathrm{~s}$ rDNA/rRNA amplicon sequencing was conducted. A total of 2,017,972 raw reads were generated from 20 tobacco samples. After quality filtering, 1,008,986 (50\%) of high-quality sequences with a mean length of $411 \mathrm{bp}$ were obtained. Operational taxonomic units (OTUs) were performed based on the $97 \%$ unique sequence similarity. Thus, 1538 OTUs were detected among 20 samples.

\section{Alpha-diversity analysis}

We further evaluated the bacterial diversity of all tobacco samples depending on the different fermentation time based on ace, Chao, Shannon, and Simpson indexes. The ace and Chao were used to identify the community richness, whereas Shannon and Simpson were used to evaluate community diversity. Ideally, higher Shannon value indicated higher diversity, while the higher Simpson index showed lower diversity. As shown in Fig. 3, bacterial richness and community diversity increased with prolonging fermentation time, but there was no significant difference in bacterial diversity between group 3 and 4. Additionally, Shannon and Sobs rarefaction curves for each sample are shown in Supplementary Figure 4, indicating the reasonable volume of sequencing data.

\section{Taxonomic composition}

The taxonomic composition was performed using the analytical program QIIME, and the Venn diagram showed the number of shared and unique OTUs in different groups (Fig. 4a). Additionally, the sequences were classified from kingdom to species. In total, five different phyla were mainly identified among these samples (Fig. 4b). Cyanobacteria (80\%) and Proteobacteria (17\%) were the dominant bacteria in group 1; Cyanobacteria, Proteobacteria, and Actinobacteria were the prevalent bacteria in group 2, representing respectively $67 \%, 34 \%$, and $5 \%$ of total sequences; Cyanobacteria (44\%), Proteobacteria (40\%), and Actinobacteria (10\%) were the most frequently detected phyla in the group 3; Cyanobacteria, Proteobacteria, Firmicutes, and Actinobacteria were mainly identified bacterial strain in group 4, accounting for $46 \%, 34 \%, 7 \%$, and $4 \%$ of all reads, respectively. We found that the abundance of Firmicutes increased with the prolongation of fermentation time, and change in the Proteobacteria population showed the same trend.

At the genus level, the raw sequences were mainly assigned into 17 different genera (Fig. 4c). In the group 1, norank_o_Chloroplast (82\%), Sphingomonas (5\%), Pantoea (4\%), and Methylobacterium (4\%) were primary genera; in the group 2, norank_o_Chloroplast (57\%), Pantoea (13\%), Pseudomonas (7\%), and Methylobacterium (4\%) were dominant bacteria; additionally, norank o_Chloroplast, Pseudomonas, and Rothia were frequently identified in the group 3 , representing $45 \%, 10 \%$, and $7 \%$ of sequencing analysis, respectively; in the group 4 , the most abundant genus were norank_o_CChloroplast (54\%), Pseudomonas (11\%), Pantoea (9\%), Burkholderia (5\%), and Ralstonia (4\%).

\section{Beta-diversity analysis}

We further evaluated the impact of fermentation time on microbial tobacco structure by PCA, principal coordinate analysis (PCoA), and non-metric multidimensional scaling (NMDS) analysis (Supplementary Figure 5). In the PCA plot, the data of group 2, group 3, and group 4 were far separated from group 1 , suggesting that fermentation had a significant effect on bacterial diversity in tobacco leaves. However, the PCoA and NMDS plots showed no separation among these groups.

\section{The differences in community composition of samples}

In order to further analyze the changes of microbiota during fermentation, we identified the differential OTUs among different groups (Fig. 5). The bar chart exhibited the 15 differential OTUs in groups; among those, three OTUs had statistically differences, including OTU124 (norank_o_Chloroplast), OTU1496 (Sphingomonas), and OTU1433 (Methylobacterium). The abundance of norank_o_Chloroplast decreased in groups 2 and 3, while it was increased in group 4. Moreover, the abundance of both Sphingomonas and Methylobacterium was reduced with the extension of fermentation time.

Furthermore, the KEGG pathway enrichment analysis of OTUs was performed. The results revealed that identified OTUs were mainly involved in the biosynthesis of ansamycins, biosynthesis of siderophore group nonribosomal peptides, and other glycan degradation and isoflavonoid biosynthesis processes (Supplementary Table 3).

\section{The integrated results analysis}

The pathways obtained both in $16 \mathrm{~s}$ rDNA/rRNA sequencing and metabolome were integrated, and the same or similar pathways were selected. A total of three pathways were identified, including biosynthesis of 


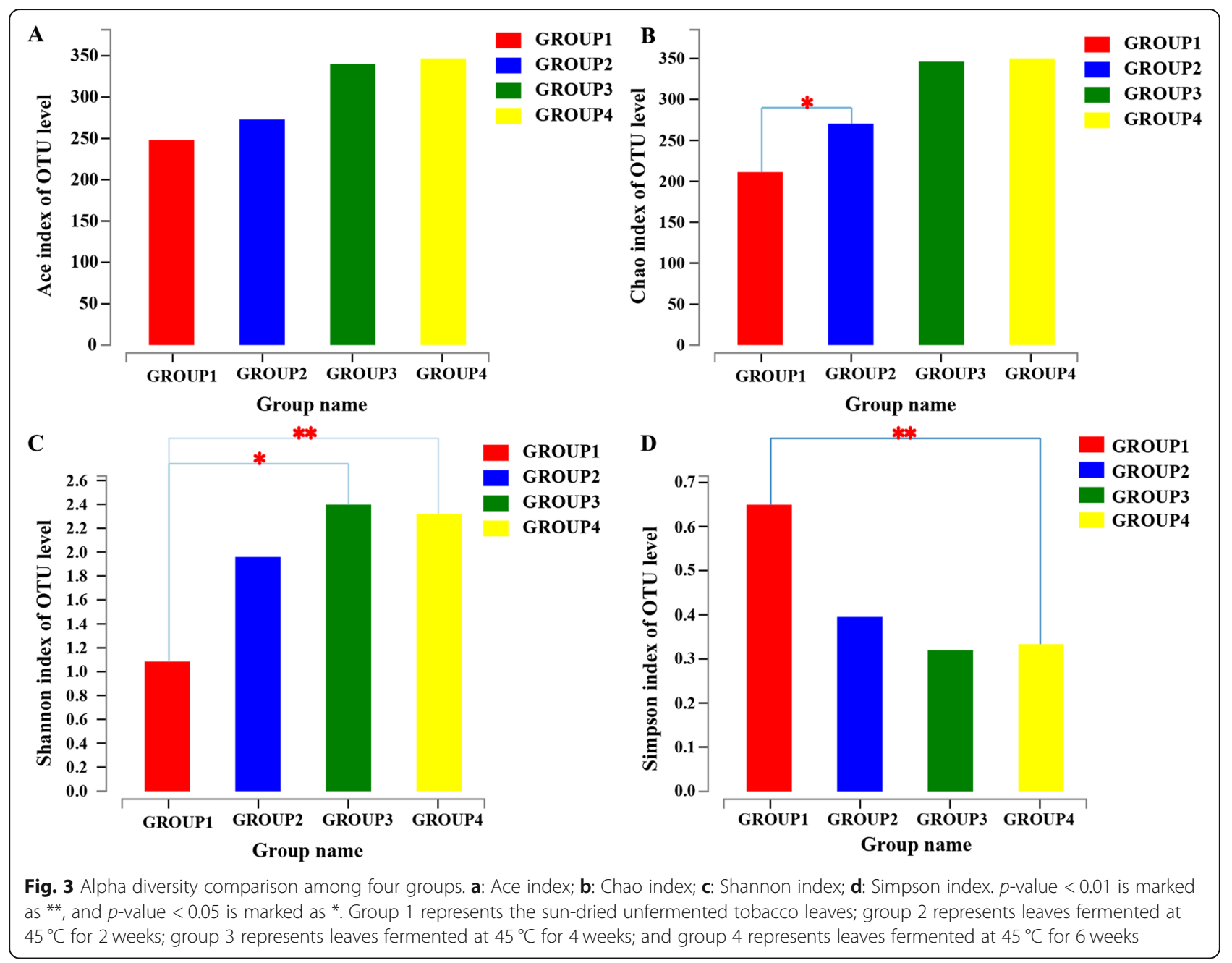

siderophore group nonribosomal peptides, $\mathrm{ABC}$ transporters, and sphingolipid metabolism (Fig. 6). In particular, 2,3-Dihydroxybenzoic acid might be involved in biosynthesis of siderophore group nonribosomal peptides; L-Histidine, L-Phenylalanine, and betaine might participate in $\mathrm{ABC}$ transporters; as well as phytosphingosine, sphingosine, and 3-ketosphinganine might be relevant to sphingolipid metabolism.

\section{Discussion}

Tobacco fermentation is a crucial part of cigarette processing, which is affected by fermentation temperature and period. However, the appropriate fermentation conditions of different varieties of tobacco leaves are different. In the present study, we identified the proper fermentation conditions of Shiyan No.1, and investigated the principal metabolites as well as dominant bacteria under suitable fermentation conditions. Based on the results of physical properties, chemical compositions, and sensory quality in the fermented tobacco (Table 1, 2, 3 and 4), we detected that fermentation at $45^{\circ} \mathrm{C}$ for 6 weeks was a mostly favorable condition, which was basically consistent with the commercial tobacco fermentation conditions. As for the tobacco leaves fermented in different periods at $45^{\circ} \mathrm{C}$, both the altered metabolites and OTUs were involved in three pathways, namely, biosynthesis of siderophore group nonribosomal peptides, ABC transporters, and sphingolipid metabolism (Fig. 6). Notably, the abundance of Pseudomonas was increased with the extension of time, while the abundances of Sphingomonas and Methylobacterium were reduced (Fig. 4). We also observed that the concentrations of Lphenylalanine and sphingosine were increased, while the concentrations of betaine and phytosphingosine were decreased in group 4 than control. Therefore, we speculated that these microflora and metabolites might play roles during the tobacco fermentation process.

In the taxonomic composition analysis, we observed that the abundance of Pseudomonas was elevated with the extension of fermentation time (Fig. 4). Despite 


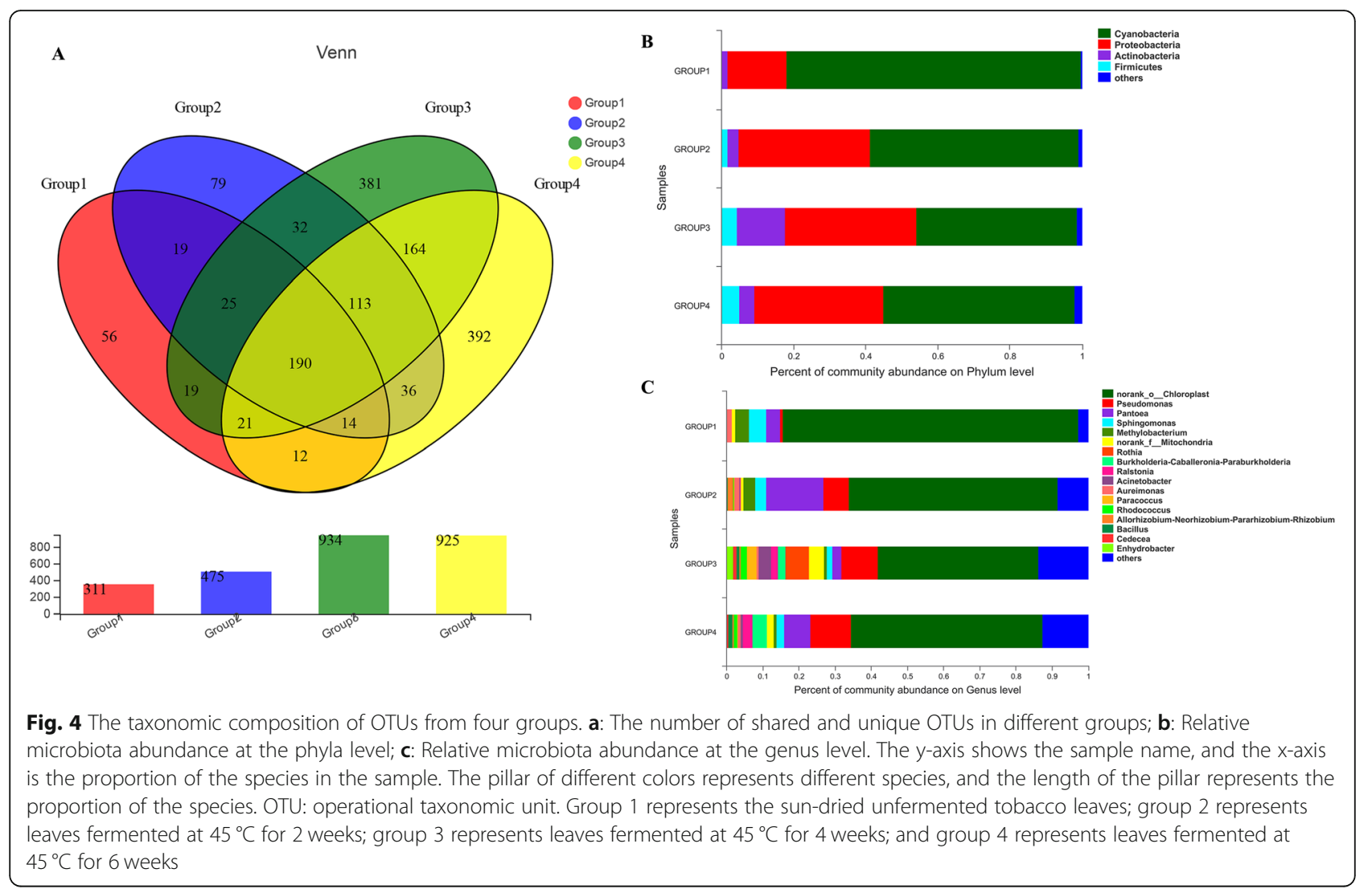

nicotine plays a significant role in the cigarette properties, it is harmful to human health [24]. Thus, it is necessary to screen microbiotas with the ability to degrade nicotine. Previous studies indicated that Pseudomonas spp. were capable of degrading nicotine $[25,26]$. Yu et al. [27] also observed that Pseudomonas was a dominant bacteria in nicotine degradation and nicotine served as the unique carbon and nitrogen source for it. Other studies further revealed that nicotine could be degraded by Pseudomonas, demonstrating that this process was achieved through the pyrrolidine pathway [28, 29]. Nicotine is the chemical that causes addiction to tobacco products. In addition, nicotine and other chemical compounds produced by the burning of tobacco are primary causes of health harm, such as lung disease [30], respiratory disease [31], and cancer [32]. Ebrahimpour et al. [33] observed that nicotine might downregulate antiinflammatory microRNAs and stimulate growth factors to accelerate the idiopathic pulmonary fibrosis process. Thus, the focus of reducing tobacco harm should be to decrease the content of nicotine level in tobacco products and change the addictive nature of combustible cigarettes [34].

In the present study, we found a significantly lower content of nicotine in fermentation at $45^{\circ} \mathrm{C}$ for 6 weeks than that in the other groups (Table 3). At the same time, the abundance of Pseudomonas was correspondingly higher than that under other conditions. Furthermore, sensory evaluation indicated that the sensory qualities of fermentation at $45{ }^{\circ} \mathrm{C}$ for 6 weeks were the best among the tested groups (Table 4). Taken together, fermenting at $45^{\circ} \mathrm{C}$ for 6 weeks might be the optimal condition of tobacco fermentation, which not only maintained the better quality, but also had low content of nicotine and might eventually reduce harm to humans to some extent. Additionally, Sphingomonas had the ability of degrading nicotine, and might be suitable for the reduction of nicotine in tobacco [35, 36]. However, the association between microflora abundance and nicotine content was not explored in this study. Therefore, to reduce the harmful substances in cigarettes, Pseudomonas and Sphingomonas could be added in the tobacco fermentation, and this is the focus of our further research.

Metabolome analysis showed that sphingolipid metabolism was an essential pathway during tobacco fermentation (Fig. 6). Sphingolipids are considered as modulators of cellular interaction and recognition [37]. The functions of sphingolipids are diverse, including cell death, inflammation, and immune responses. In addition, 


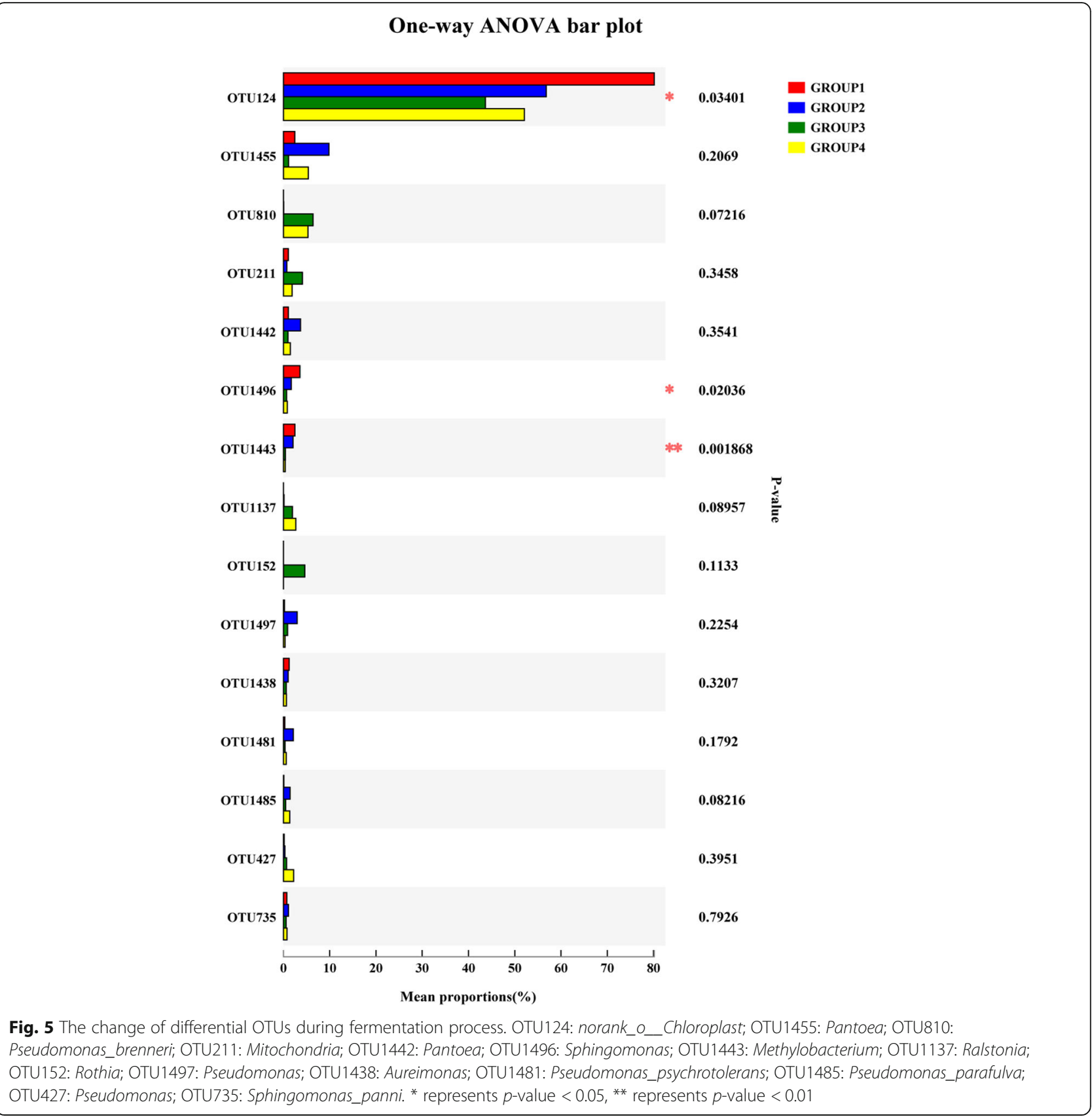

sphingolipids have been reported to play roles in modulating cancer signaling to control tumor suppression or survival [38], and sphingosine 1-phosphate (S1P) is a bioactive molecule within sphingolipid metabolites [39]. Chen et al. [40] indicated that significant emphysema changes were observed in the pulmonary parenchyma of smoker mice, where the level of S1P was increased in the lungs of cigarette smoke-exposed mice. Meanwhile, sphingomyelinase 2 is activated by smoking and induces the apoptosis of lung cells [41]. These studies suggest that sphingolipids and their metabolism are closely associated with the development and treatment of lungrelated diseases caused by smoking. In this study, we found that phytosphingosine might be involved in the sphingolipid metabolism pathway, showing significant increase with the extension of fermentation time. Phytosphingosine participates in diverse cellular processes. Xiong et al. [42] revealed that phytosphingosine level was reduced in the lung tissue of acute lung injury mouse models. Moreover, Park et al. [43] found that phytosphingosine could induce non-small cell lung carcinoma cells apoptosis. In the current study, we found 


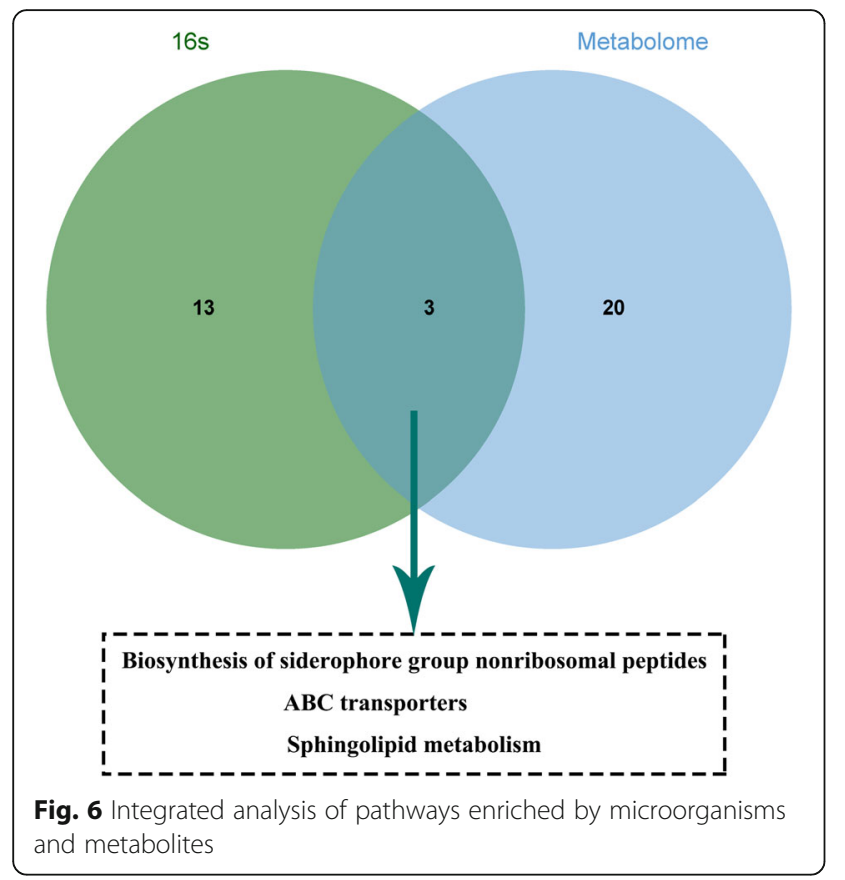

that the level of phytosphingosine was the highest at 6 weeks of fermentation (Supplementary Table 1). Based on the above reports, we speculated that phytosphingosine might alleviate the lung damage caused by harmful substances in smoke to a certain extent. Another metabolite, sphingosine, was also enriched in the sphingolipid metabolism pathway (Supplementary Table 2). Sphingosine is reported to be related to the development of cancer and inflammation [44]. Besides, evidence showed that sphingosine was associated with lung carcinoma signaling pathways which were activated by smoking [45]. Tobacco carcinogen NNK can activate a Raf-1/MAP kinase pathway and stimulate cell proliferation in human small cell lung carcinoma cells, while sphingosine might block this process $[46,47]$. Moreover, we found an increase of sphingosine level in fermentation for 6 weeks (Supplementary Table 1). Taken together, these studies further indicated that fermentation at $45^{\circ} \mathrm{C}$ for 6 weeks might be the optimum conditions, and phytosphingosine as well as sphingosine might reduce the harm of hazardous substances to the human body via sphingolipid metabolism pathway. However, the specific function of phytosphingosine and sphingosine in tobacco fermentation remains to be further study. Furthermore, the mechanisms of tobacco damage reduction through specific metabolites need further experimental verification.

\section{Conclusion}

In summary, the changes in the microbial community and metabolites during the tobacco fermentation process were systematically studied. Fermentation at $45^{\circ} \mathrm{C}$ for 6 weeks was considered to be the optimum fermentation condition due to it maintained favorable sensory qualities of tobacco and reduced the nicotine content to a certain extent. The microorganisms (such as Pseudomonas and Sphingomonas) and metabolites (such as phytosphingosine and sphingosine) had crucial roles in the tobacco fermentation. Additionally, metabolites might affect the quality of cigarettes through the sphingolipid metabolism pathway. However, the underlying mechanisms of the relationship between microbiota and metabolites warrant further investigation.

\section{Methods}

\section{Sample collection and tobacco fermentation}

Tobacco samples (Shiyan No.1) were grown in Deyang (Sichuan, China). After ripening, the middle leaves were harvested and sun-dried for 5 weeks. Then, the sundried tobacco was stacked in the fermentation room. The tobacco leaves were fermented at $25^{\circ} \mathrm{C}, 35^{\circ} \mathrm{C}$, and $45^{\circ} \mathrm{C}$ (90\% relative humidity), and samples were collected after 2, 4, and 6 weeks, respectively. Additionally, the sun-dried unfermented tobacco leaves were considered as control group. To ensure the uniformity of the samples, the tobacco leaves were collected from five different parts of the tobacco stack and mixed as samples of each group. The fermentation process was performed in triplicate. Then, the quality and sensory evaluation of fermented tobacco leaves were detected. The measurement was repeated five times.

\section{Physiological indicators and sensory evaluation Determination of aroma components}

The content of aroma components in tobacco leaves was determined using pre-treatment of $\mathrm{n}$-hexane extraction at room temperature improved by Shanghai tobacco technology center and liquid chromatography-gas chromatography (LC-GC) technique [48]. Approximately 0.2 $\mathrm{g}$ of powder samples were weighed and put into a $20 \mathrm{~mL}$ tube, supplemented with $5 \mathrm{~mL}$ extraction solvent (n-hexane: Tert-butyl methyl ether, $\mathrm{v}: \mathrm{v}=1: 1$ ) and $200 \mu \mathrm{L}$ internal standard solution ( $\alpha$-ionone, $11.2 \mu \mathrm{g} / \mathrm{mL}$ ). After standing for $24 \mathrm{~h}$ at $25^{\circ} \mathrm{C}$, the solution was vortexed for $1 \mathrm{~min}$ and then centrifuged at $3000 \mathrm{rpm}$ for $10 \mathrm{~min}$. Then, $2 \mathrm{~mL}$ of the supernatant was extracted and transferred to a chromatographic tube. The LC analysis was performed on an Agilent 1260 system (Agilent Technologies, USA) using a Waters Styragel HR 0.5 column $(30 \mathrm{~cm} \times 4.6 \mathrm{~cm}$ i.d., $5 \mathrm{~m})$ (Waters Corp., USA). Dichloromethane was used as mobile phase, the flow rate was $0.25 \mathrm{~mL} / \mathrm{min}$, the column was maintained at $30^{\circ} \mathrm{C}$, and the injection volume was $20 \mu \mathrm{L}$. The diode array detector (DAD) detection wavelengths were $238 \mathrm{~nm}, 254 \mathrm{~nm}$, and $320 \mathrm{~nm}$. Meanwhile, the LC-GC transfer was performed as described by Qi et al. [48]. The GC analysis was 
employed on an Agilent 7890A GC system (Agilent Technologies, USA) equipped with electron caputure detector (ECD). Then, GC/MS separation was performed on a DB-5MS capillary column $(30 \mathrm{~m} \times 0.25 \mathrm{~mm}$ i.d., $0.25 \mathrm{~m} \mathrm{df}$ ) from Agilent Technologies (USA). The oven temperature was maintained at $40{ }^{\circ} \mathrm{C}$ for $14 \mathrm{~min}$, then increased to $290^{\circ} \mathrm{C}$ at $4{ }^{\circ} \mathrm{C} / \mathrm{min}$ and maintained for $5 \mathrm{~min}$. The GC/MS transmission line temperature was $280^{\circ} \mathrm{C}$, the MS ion source temperature was $230^{\circ} \mathrm{C}$, quadrupole temperature was $170^{\circ} \mathrm{C}$, and mass ranged from 45 to $350 \mathrm{amu}$. Chemical components detected in GC-MS analysis were identified using NIST98 and Wiley 6.0 library software.

\section{TSNAs, alkaloids, and nitrate assays}

TSNAs assays were performed by Shanghai Tobacco Group Beijing Cigarette Factory using online solid-phase extraction (SPE)-LC-MS/MS (SPE-LC: Spark Holland, Symbiosis Pico; MS/MS: AB Sciex triple quad 5500) [49]. Four common TSNAs, including $\mathrm{N}^{\prime}$-nitrosonornicotine $(\mathrm{NNN}), \mathrm{N}^{\prime}$-nitrosoanatabine (NAT), $\mathrm{N}^{\prime}$-nitrosoanabasine (NAB), and NNK, were tested. Samples (1.0 g) were transferred into a $50 \mathrm{~mL}$ conical flask. Then, four deuterated internal standard solutions $(40 \mu \mathrm{L})$ and 30 $\mathrm{mL}$ ammonium acetate solution $(100 \mathrm{mmol} / \mathrm{L})$ were added. The sample was shaken and extracted at $25^{\circ} \mathrm{C}$ for $60 \mathrm{~min}(200 \mathrm{r} / \mathrm{min})$ and then filtered with a $0.45 \mu \mathrm{m}$ Water phase filter membrane. After collecting the filtrate, LC-MS/MS was used to detect the content of NNN, NAT, NAB, and NNK. The sum of the four TSNAs represented the total amount of TSNAs.

Alkaloids detection was conducted based on previously published methods [50]. Briefly, $200 \mathrm{mg}$ of the sample was weighed and put into a $10 \mathrm{~mL}$ glass bottle. Next, 1.5 $\mathrm{mL} 10 \% \mathrm{NaOH}$ solution and $3 \mathrm{~mL}$ methyl tert-butyl ether were added. The mixed solution was shaken for 5 min and kept standing for $24 \mathrm{~h}$. Then, the supernatant was extracted and passed through gas chromatographyHydrogen flame ionization detector (Agilent 7890A, Agilent Technologies, USA) to detect four alkaloids, including nicotine, nornicotine, neonicotine, and anatabine.

The nitrate content was detected following the method described by $\mathrm{Da}$ et al. [50]. For that, $400 \mathrm{mg}$ of cigarette sample in a triangular flask was re-suspended in $50 \mathrm{~mL}$ $1 \% \mathrm{CH}_{3} \mathrm{COOH}$ solution and shaken for $20 \mathrm{~min}$. After $\mathrm{NO}_{3}$ - was extracted and filtered, the activated carbon was supplemented for decolorization and the solution was filtered. After that, $15 \mathrm{mg}$ of zinc powder was added and the sample was subjected to a slight oscillation for $15 \mathrm{~min}$. Two $\mathrm{mL}$ nitrate reagent was added to the $8 \mathrm{~mL}$ of the intermediate filtrate, and let standing for $15 \mathrm{~min}$. The absorbance was determined on a 721 spectrophotometer at a wavelength of $540 \mathrm{~nm}$ using a blank reagent as a reference.

\section{Sensory quality evaluation}

Samples were cut into rolls to make cigarettes, and then evaluated by seven experts from the Technology Center of Henan China Tobacco Industry Co., Ltd. and the Tobacco College of Henan Agricultural University. Sensory quality was calculated according to the standard of the reference YC/T138-1998 of China [11]. Specifically, this measure contained 9 items rated on a nine-point scale, ranging from 0 to 9 score. The quality indexes contained aroma quality, aroma quantity, smoke density, offensive odor, physiological strength, irritation, aftertaste, combustibility, and cigarette ash. Furthermore, the result of each index was the average of seven people's scores.

\section{Metabolomics analysis}

\section{Sample preparation and LC-MS analysis}

The quality detection and sensory analysis showed that $45^{\circ} \mathrm{C}$ was the optimal temperature for the fermentation process. Thus, we selected tobacco leaves fermented at $45^{\circ} \mathrm{C}$ for 2 weeks, 4 weeks, and 6 weeks for metabolomics analysis. The sun-dried unfermented tobacco leaves served as control. The groups were designated as group 1 (control), group 2 ( 2 weeks), group 3 (4 weeks), and group 4 (6 weeks), with five samples in each group.

Metabolomics analysis was performed using LC-MS. In brief, $0.2 \mathrm{~g}$ tobacco powder of each sample was weighed and put into $20 \mathrm{~mL}$ tubes. The metabolites were extracted by adding $5 \mathrm{~mL}$ n-hexane:tert-butyl methyl ether solution (v:v, 1:1) and $200 \mu \mathrm{L} \alpha$-Ionone $(11.2 \mu \mathrm{g} /$ $\mathrm{mL}$ ) internal standard solution. After standing for $24 \mathrm{~h}$ at room temperature, the samples were vortexed at 200 $\mathrm{rpm}$ for $1 \mathrm{~min}$. The mixture was centrifuged at $2000 \mathrm{rpm}$ for $10 \mathrm{~min}$. Finally, $2 \mathrm{~mL}$ supernatant was placed in an LC-MS sample bottle for detecting. The method of LCMS analysis was consistent with the detection of aroma components as described above.

\section{Data pre-processing and analysis}

The raw data obtained from LC-MS were pre-processed using the Progenesis QI (Waters Corporation) software, including missing value recoding and normalization. Then, a data matrix was obtained and converted using the SIMCA-P 14.1 software (Umetrics, Umea, Sweden). According to the expression of metabolites, the PCA was performed to evaluate the similarity of samples within groups and the difference of samples among groups. Moreover, to investigate the biological functions of metabolites, the KEGG [4] and HMDB 4.0 [5] databases were applied to perform identification and annotation.

\section{Identification of the differential metabolites}

To obtain the differential metabolites between different groups (group 2 vs. group 1, group 3 vs. group 1, and group 4 vs. group 1), the multiple statistical methods and 
significance difference test were performed. A series of statistical analyses, including PCA, supervised partial least-squares discriminant analysis (PLS-DA), and orthogonal partial least-squares discriminant analysis (OPLSDA), were applied. Differential metabolites were identified based on the statistically significant threshold of VIP values obtained from the OPLS-DA model and $p$-value from Student's $t$-test on the normalized peak areas. Metabolites with VIP $>1$ and $p$-value $<0.05$ were considered statistically significant. Meanwhile, the ellipse in the plots showed the Hotelling's T2 confidence region, which defined the $95 \%$ confidence interval $(\mathrm{CI})$ of the modeled variation. The PLS-DA and OPLS-DA models were verified using a permutation test repeated 200 times.

\section{Metabolic pathway enrichment analyses}

To observe the distribution of metabolites in each group, a Venn diagram was generated. Moreover, the metabolite information in the pathways was extracted based on the KEGG database, and the pathway of differential metabolites was obtained using the hypergeometric test method. The $p$-value was corrected by using the Benjamini-Hochberg (BH) method, and $p$-value $<0.05$ was set as the cut-off criteria.

\section{$16 \mathrm{~s}$ rDNA/rRNA amplicon sequencing and analysis DNA extraction from the tobacco leaves and sequencing approach}

In order to investigate the changes of microbiota during the fermentation process, $16 \mathrm{~s}$ rRNA gene sequencing was also performed for these four groups, with each group included five samples. Ten grams of tobacco leaves of each sample were collected and placed in a flask with $250 \mathrm{~mL}$ sterilized $0.1 \mathrm{M}$ phosphate buffer $(\mathrm{pH}$ 7.0) for $30 \mathrm{~min}$. Later, the tobacco leaves were washed with a sonicator for $10 \mathrm{~min}$ and the microorganisms were collected by centrifugation at 10,000×g for $30 \mathrm{~min}$. Total microbial genomic DNA was extracted using an ExPro Tobacco DNA Kit (Gene Answer) based on the guides provided by the manufacturer. The genomic DNA isolated from samples was used as template for $16 \mathrm{~S}$ rRNA gene amplification. The V3-V4 regions of the $16 \mathrm{~s}$ rRNA gene (from 338F to 806R) were amplified from DNA using previously published primers [51]. PCR amplification was conducted using TransStart ${ }^{\circ}$ Fastpfu DNA Polymerase kit on the ABI GeneAmp 9700 (Applied Biosystems) and each sample was assayed in triplicate. Then, PCR products were detected using $2 \%$ agarose gel electrophoresis and recovered using an AxyPrepDNA Gel Recovery Kit (Axygen Bioscience), followed by elution with Tris- $\mathrm{HCl}$. Then, the PCR products were quantified using QuantFlour ${ }^{\mathrm{Tm}}-\mathrm{ST}$ Blue Fluorescence Quantitative System (Promega) and the amplicon was sequenced using Illumina MiSeq platform.
The raw sequencing files of twenty tobacco samples were uploaded in the NCBI SRA database (http://www. ncbi.nlm.nih.gov/bioproject/660877) under the accession number of PRJNA660877.

\section{Bioinformatics analysis}

The raw sequencing data were de-multiplexed and quality controlled by FLASH Trimmomatic software [52]. The high-quality sequencing reads were analyzed and clustered into OTU using Usearch (version: 7.0, http:// drive5.com/usearch/) with a $97 \%$ similarity threshold. Additionally, taxonomic assignments of OTUs were conducted using the QIIME (version: 1.9.0, http://qiime.org/ scripts/assign_taxonomy.html) software through comparison with RDP classifier (version: 2.2, http://sourceforge.net/projects/rdp-classifier/) and Silva database (release 128, http://www.arb-silva.de). Based on the OTUs table, the alpha-diversity analysis was performed, which evaluated the species diversity of samples via calculating Ace, Chao, Shannon, and Simpson indexes. The $t$-test was used to assess the significant difference between groups, and results were visualized using the $R$ software (version: 2.15.3, http://www.R-project.org). Besides, the rarefaction curve was analyzed using the Mothur (version: 1.39.5, https://mothur.org/). To further analyze the species composition, the Venn diagram was used to count the number of the common and unique OTUs in multiple samples, and the pie-chart was utilized to show the relative abundance of each microbiota in the samples. The beta-diversity analysis was aimed to examine the similarity of community structure among groups. In this study, beta-diversity results were visualized using PCA, PCoA, and NMDS plots. Differential OTUs were identified using analysis of variance (ANOVA), and $p$-value $<0.05$ was defined as statistically significant. In addition, the phylogenetic investigation of communities by reconstruction of unobserved states program (PICRUSt) was applied to predict the function of microbiota and $p$-value less than 0.05 was set as the threshold of significant enrichment.

\section{Integration of amplicon sequencing and metabolomics analysis}

For studying the relationship between microbiota and metabolites, an integration analysis was performed. According to the results of KEGG pathways analysis, the same or similar pathways, which existed both in $16 \mathrm{~s}$ rRNA gene sequencing and metabolome analysis, were selected.

\section{Statistical analysis}

One-way ANOVA with Bonferroni's multiple comparisons test and Student's $t$-test were performed using SPSS 17.0 software (IBM, USA). The significance threshold was set at $p$-value $<0.05$. 


\section{Supplementary Information}

The online version contains supplementary material available at https://doi. org/10.1186/s12866-020-02035-8.

Additional file 1: Supplementary Figure S1. The primary

physicochemical indexes of fermented tobacco leaves. A: NNN; B: TSNAs; C: Alkaloids; D: Nitrates. NNN: N'-nitrosonornicotine; TSNAs: Tabaccospecific Nitrosamines. Error bars represent standard errors.

Additional file 2: Supplementary Figure S2. Score scatter plot of the PCA model. A: POS mode; B: NEG mode. PCA: principal component analysis; POS: positive; NEG: negative. Group 1 represents the sun-dried unfermented tobacco leaves; group 2 represents leaves fermented at $45^{\circ} \mathrm{C}$ for 2 weeks; group 3 represents leaves fermented at $45^{\circ} \mathrm{C}$ for 4 weeks; and group 4 represents leaves fermented at $45^{\circ} \mathrm{C}$ for 6 weeks; QC represents quality control group.

Additional file 3: Supplementary Figure S3. PCA model score scatter plot, PLS-DA model, and OPLS-DA model for the different groups. A: PCA model from NEG; B: PCA model from POS; C: PLS-DA model from NEG; D: PLS-DA model from POS; E: OPLS-DA model from NEG; F: OPLS-DA model from POS. PLS-DA: partial least squares-discriminant analysis; OPLS-DA: orthogonal partial least squares-discrimination analysis.

Additional file 4: Supplementary Figure S4. The rarefaction curves for each sample. A: Shannon value; B: Sobs value.

Additional file 5: Supplementary Figure S5. The beta diversity comparison among four groups. A: PCA plot; B: PCoA plot; C: NMDS plot. PCoA: principal-coordinate analysis; NMDS: non-metric multidimensional scaling.

Additional file 6: Supplementary Table S1. The detail information of annotated metabolites. (XLS $393 \mathrm{~kb}$ )

Additional file 7: Supplementary Table S2. Top 20 KEGG pathway and enriched metabolites. Supplementary Table S3. Top 20 KEGG pathways of differential OTUs.

\section{Abbreviations}

RH: Relative humidity; TSNAs: Tobacco-specific nitrosamines; LC-MS: Liquid chromatography-mass spectrometry; PCA: Principal component analysis; POS: Positive; NEG: Negative; KEGG: Kyoto Encyclopedia of Genes and Genomes; HMDB: Human Metabolome Database; VIP: Variable importance in the projection; OTUs: Operational taxonomic units; PCoA: Principal coordinate analysis; NMDS: Non-metric multidimensional scaling; S1P: Sphingosine 1-phosphate; LC-GC: Liquid chromatography-gas chromatography; ECD: Electron caputure detector; SPE: Solid-phase extraction; NNN: N'-nitrosonornicotine; NAT: N'-nitrosoanatabine; NAB: N '-nitrosoanabasine; PLS-DA: Partial least-squares discriminant analysis; OPLSDA: Orthogonal partial least-squares discriminant analysis; Cl: Confidence interval; BH: Benjamini-Hochberg

\section{Acknowledgements}

None.

\section{Authors' contributions}

Conception and design of the research: HS, YQ; acquisition of data: YZ; analysis and interpretation of data: $Y Z, Y Q$; statistical analysis: $Y Z$; obtaining funding: HS; drafting the manuscript: $J$; revision of manuscript for important intellectual content: HS. All authors read and approved the final manuscript.

\section{Funding}

This work was supported by Research and Application of Key Technologies to Reduce TSNAs in Cigar Tobacco Leaves [grant number SCYC201915] and Key Science and Technology Project of Sichuan Tobacco Company. The funder had no role in study design, data collection and analysis, decision to publish, or preparation of the manuscript.

\section{Availability of data and materials}

The dataset generated or analyzed and strain used in the current study were submitted to NCBI SRA database with the accession no. PRJNA660877.
Ethics approval and consent to participate

Not applicable.

\section{Consent for publication}

Not applicable.

\section{Competing interests}

The authors declare that they have no conflicts of interest.

\section{Author details}

${ }^{1}$ College of Tobacco Science, Henan Agricultural University, No. 95 Wenhua Road, Zhengzhou 450002, Henan Province, China. ${ }^{2}$ Sichuan Tobacco

Company, Chengdu, Sichuan, China.

Received: 29 May 2020 Accepted: 5 November 2020

Published online: 19 November 2020

\section{References}

1. Zappe AL, Fernandes de Oliveira P, Boettcher R, Rodriguez AL, Machado ÊL, Mantey Dos Santos PA, Rodriguez Lopez DA, Amador de Matos MA. Human health risk and potential environmental damage of organic and conventional Nicotiana tobaccum production. Environ pollut. 2020;266(Pt 2): 114820

2. Xu X, Zhang X, Hu TW, Miller LS, Xu M. Effects of global and domestic tobacco control policies on cigarette consumption per capita: an evaluation using monthly data in China. BMJ Open. 2019;9(6):e025092.

3. Frankenburg WG. Chemical changes in the harvested tobacco leaf. II. Chemical and enzymic conversions during fermentation and aging. Adv Enzymol Relat Subj Biochem. 1950;10:325-441.

4. $\quad$ Yang $Y$, Peng $Q$, Ou M, Wu Y, Fang J. Research progress in tobacco fermentation. J Biosci Med. 2018;6(06):105-14.

5. Liu C, Liu C, Wang G, Li H, Jin Z, Xia Y. Research progress on tobacco leaf fermentation. Guangxi J Light Industry. 2011:27(11):15-6.

6. Wan D, Wu C, Du J, Mo J, Yao F, Shi X. Research advances in fermentation methods of cigar tobacco leaves. J Shanxi Agricultural Sciences. 2017;45(07): $1211-4$

7. Guo X, Jin B, Shen G. Tobacco fermentation: a review. Tobacco Science \& Technology. 2004;11:7-14

8. Zhou J, Tang Z. Progress and prospect of cigar fermentation technology. Agricultural Technology Service. 2009;26(11):119-20.

9. Wang J, Zeng D, Fu L, Zhu C, Shi X. Research progress of air-cured tobacco fermentation. Journal of Henan Agricultural Sciences. 2014:43(4):1-4.

10. Zhou W, Liu Y, Zeng D, Yang J, Hu X, Song S, Liu L, Jia Y, Yang Z, Liu Y, et al. The study and application of cigar filler stacking fermentation technology. Hans J Agric Sci. 2016;6(3):63-70.

11. Yang Z, Zhang J, Song S, Zhang L, Jia Y, Liu L, Chen X, Liu Y, Zhou W. Effects of two different fermentation methods on the chemical composition and sensory quality of sun-cured tobacco leaves. J Anhui Agric Sci. 2018; 46(6):8-11.

12. Li J, Shi H, Yang $X$, Zhou J, Bai R, Qin Y, Yang W. Effects of fermentation conditions on content of TSNAs and their precursors in cigar filler tobacco. Acta Tabacaria Sinica. 2019;25(06):120-5.

13. Wei $X$, Deng $X, C$ Cai D, Ji Z, Wang C, Yu J, Li J, Chen S. Decreased tobaccospecific nitrosamines by microbial treatment with Bacillus amyloliquefaciens DA9 during the air-curing process of burley tobacco. J Agric Food Chem. 2014;62(52):12701-6

14. Popova V, Ivanova T, Prokopov T, Nikolova M, Stoyanova A, Zheljazkov VD. Carotenoid-related volatile compounds of tobacco (Nicotiana tabacum L.) essential oils. Molecules. 2019;24(19):3446.

15. Sarlak S, Lalou C, Amoedo ND, Rossignol R. Metabolic reprogramming by tobacco-specific nitrosamines (TSNAs) in cancer. Semin Cell Dev Biol. 2020; 98:154-66.

16. Rickert WS, Joza PJ, Sharifi M, Wu J, Lauterbach JH. Reductions in the tobacco specific nitrosamine (TSNA) content of tobaccos taken from commercial Canadian cigarettes and corresponding reductions in TSNA deliveries in mainstream smoke from such cigarettes. Regul Toxicol Pharmacol. 2008;51(3):306-10.

17. Reid J McKinstry DW, Haley DE. The fermentation of cigar-leaf tobacco. Science. 1937;86(2235):404 
18. Di Giacomo M, Paolino M, Silvestro D, Vigliotta G, Imperi F, Visca P, Alifano P, Parente D. Microbial community structure and dynamics of dark firecured tobacco fermentation. Appl Environ Microbiol. 2007;73(3):825-37.

19. Shan H, Chen D, Li J, Chen T, Hu H, Guo Z, An D. Identification and primary application of TSNA degrading bacterial strain AS97 isolated from aging tobacco leaves. Acta Microbiol Sin. 2011;51(10):1326-33.

20. Su Y, Wang Q, Zhang C, Gu J, Shi S, Manik S, Mao J, Li S, Lei Q, Wu R, et al. Isolation of microorganisms producing enzyme capable of degrading tobacco straw and nicotine. Acta Microbiol Sin. 2015;55(12):1543-50.

21. Vigliotta G, Di Giacomo M, Carata E, Massardo DR, Tredici SM, Silvestro D, Paolino M, Pontieri P, Del Giudice L, Parente D, et al. Nitrite metabolism in Debaryomyces hansenii TOB-Y7, a yeast strain involved in tobacco fermentation. Appl Microbiol Biotechnol. 2007;75(3):633-45.

22. Yu J, Li L, Pang T, Ren X, Shao H. Research advancement of tobacco fermentation. J Henan Agricultural University. 2006;40(1):108-12.

23. Li Z, Wang L, Yang G, Shi H, Jiang C, Liu W, Zhang Y. Study on the determination of polyphenols in tobacco by HPLC coupled with ESI-MS after solid-phase extraction. J Chromatogr Sci. 2003;41(1):36-40.

24. Mishra A, Chaturvedi P, Datta S, Sinukumar S, Joshi P, Garg A. Harmful effects of nicotine. Indian J Med Paediatr Oncol. 2015;36(1):24-31.

25. Zhong W, Zhu C, Shu M, Sun K, Zhao L, Wang C, Ye Z, Chen J. Degradation of nicotine in tobacco waste extract by newly isolated Pseudomonas sp. ZUTSKD Bioresour Technol. 2010;101(18):6935-41.

26. Chen C, Li X, Yang J, Gong X, Li B, Zhang K. Isolation of nicotine-degrading bacterium Pseudomonas sp. Nic22, and its potential application in tobacco processing. Int Biodeterior Biodegradation. 2008;62(3):226-31.

27. Yu H, Tang H, Wang L, Yao Y, Wu G, Xu P. Complete genome sequence of the nicotine-degrading Pseudomonas putida strain S16. J Bacteriol. 2011; 193(19):5541-2.

28. Li H, Li X, Duan Y, Zhang K, Yang J. Biotransformation of nicotine by microorganism: the case of Pseudomonas spp. Appl Microbiol Biotechnol. 2010;86(1):11-7

29. Tang H, Yao Y, Wang L, Yu H, Ren Y, Wu G, Xu P. Genomic analysis of Pseudomonas putida: genes in a genome island are crucial for nicotine degradation. Sci Rep. 2012;2:377.

30. Maritz GS. Perinatal exposure to nicotine and implications for subsequent obstructive lung disease. Paediatr Respir Rev. 2013;14(1):3-8.

31. Spindel ER, McEvoy CT. The role of nicotine in the effects of maternal smoking during pregnancy on lung development and childhood respiratory disease. Implications for dangers of e-cigarettes. Am J Respir Crit Care Med. 2016;193(5):486-94.

32. Grando SA. Connections of nicotine to cancer. Nat Rev Cancer. 2014;14(6): 419-29.

33. Ebrahimpour A, Shrestha S, Bonnen MD, Eissa NT, Raghu G, Ghebre YT. Nicotine modulates growth factors and microRNA to promote inflammatory and fibrotic processes. J Pharmacol Exp Ther. 2019;368(2):169-78.

34. Gottlieb S, Zeller M. A nicotine-focused framework for public health. N Engl J Med. 2017;377(12):1111-4.

35. Wang M, Yang G, Wang X, Yao Y, Min H, Lu Z. Nicotine degradation by two novel bacterial isolates of Acinetobacter sp. TW and Sphingomonas sp. TY and their responses in the presence of neonicotinoid insecticides. World J Microbiol Biotechnol. 2011;27(7):1633-40.

36. Zhu X, Wang W, Xu P, Tang H. Complete genome sequence of Sphingomonas sp. strain NIC1, an efficient nicotine-degrading bacterium. Genome Announc. 2016:4(4):e00666-16.

37. Hannich JT, Umebayashi K, Riezman H. Distribution and functions of sterols and sphingolipids. Cold Spring Harb Perspect Biol. 2011;3(5):a004762.

38. Ogretmen B. Sphingolipid metabolism in cancer signalling and therapy. Nat Rev Cancer. 2018;18(1):33-50.

39. Taylor VA, Stone HK, Schuh MP, Zhao X, Setchell KD, Erkan E. Disarranged sphingolipid metabolism from sphingosine-1-phosphate lyase deficiency leads to congenital nephrotic syndrome. Kidney Int Rep. 2019;4(12):1763-9.

40. Chen J, Tang H, Sysol JR, Moreno-Vinasco L, Shioura KM, Chen T, Gorshkova I, Wang L, Huang LS, Usatyuk PV, et al. The sphingosine kinase 1/ sphingosine-1-phosphate pathway in pulmonary arterial hypertension. Am J Respir Crit Care Med. 2014;190(9):1032-43.

41. Levy M, Khan E, Careaga M, Goldkorn T. Neutral sphingomyelinase 2 is activated by cigarette smoke to augment ceramide-induced apoptosis in lung cell death. Am J Physiol Lung Cell Mol Physiol. 2009;297(1):L125-L33.
42. Xiong Z, Wang $Y$, Lang $L$, Ma S, Zhao L, Xiao W, Wang Y. Tissue metabolomic profiling to reveal the therapeutic mechanism of reduning injection on LPS-induced acute lung injury rats. RSC Adv. 2018;8(18): 10023-31.

43. Park M-T, Kang JA, Choi J-A, Kang C-M, Kim T-H, Bae S, Kang S, Kim S, Choi W-I, Cho C-K, et al. Phytosphingosine induces apoptotic cell death via caspase 8 activation and Bax translocation in human cancer cells. Clin Cancer Res. 2003;9(2):878-85.

44. Pyne NJ, McNaughton M, Boomkamp S, MacRitchie N, Evangelisti C, Martelli AM, Jiang H-R, Ubhi S, Pyne S. Role of sphingosine 1-phosphate receptors, sphingosine kinases and sphingosine in cancer and inflammation. Adv Biol Regul. 2016;60:151-9.

45. Heusch $\mathrm{WL}$, Maneckjee R. Signalling pathways involved in nicotine regulation of apoptosis of human lung cancer cells. Carcinogenesis. 1998; 19(4):551-6.

46. Wen J, Fu J-H, Zhang W, Guo M. Lung carcinoma signaling pathways activated by smoking. Chin J Cancer. 2011;30(8):551-8.

47. Jull B, Plummer $\mathrm{H}$, Schuller $\mathrm{H}$. Nicotinic receptor-mediated activation by the tobacco-specific nitrosamine NNK of a Raf-1/MAP kinase pathway, resulting in phosphorylation of c-myc in human small cell lung carcinoma cells and pulmonary neuroendocrine cells. J Cancer Res Clin Oncol. 2001:127(12):707-17.

48. Qi D, Fei T, Sha Y, Wang L, Li G, Wu D, Liu B. A novel fully automated online coupled liquid chromatography-gas chromatography technique used for the determination of organochlorine pesticide residues in tobacco and tobacco products. J Chromatogr A. 2014;1374:273-7.

49. Zhou J, Bai R, Zhu Y. Determination of four tobacco-specific nitrosamines in mainstream cigarette smoke by gas chromatography/ion trap mass spectrometry. Rapid Commun Mass Spectrom. 2007;21(24):4086-92.

50. Da Y, Fang L, Lu D, Lu Q, Xuan X. Determination of nitrate in tobacco by spectrophotometer. Chinese Tobacco Science. 2000;02:33-5.

51. Yu M, Jia H, Zhou C, Yang Y, Zhao Y, Yang M, Zou Z. Variations in gut microbiota and fecal metabolic phenotype associated with depression by 165 rRNA gene sequencing and LC/MS-based metabolomics. J Pharm Biomed Anal. 2017;138:231-9.

52. Bolger AM, Lohse M, Usadel B. Trimmomatic: a flexible trimmer for Illumina sequence data. Bioinformatics. 2014;30(15):2114-20.

\section{Publisher's Note}

Springer Nature remains neutral with regard to jurisdictional claims in published maps and institutional affiliations.

Ready to submit your research? Choose BMC and benefit from:

- fast, convenient online submission

- thorough peer review by experienced researchers in your field

- rapid publication on acceptance

- support for research data, including large and complex data types

- gold Open Access which fosters wider collaboration and increased citations

- maximum visibility for your research: over $100 \mathrm{M}$ website views per year

At $\mathrm{BMC}$, research is always in progress.

Learn more biomedcentral.com/submission 